\title{
Avasküler nekroz: etiyolojisi ve patofizyolojisi
}

\author{
Avascular necrosis: etiology and pathophysiology \\ Ahmet Murat Bülbül1', Oğuzhan Korkmaz¹, Ahmet Özgür Yıldırım² \\ ${ }^{1}$ İstanbul Medipol Üniversitesi Tıp Fakültesi, Ortopedi ve Travmatoloji Anabilim Dalı, İstanbul \\ ${ }^{2}$ Ankara Şehir Hastanesi, Ortopedi ve Travmatoloji Anabilim Dalı, Ankara
}

\begin{abstract}
Avasküler nekroz (osteonekroz, kemik infarktüsü, aseptik nekroz), çeşitli nedenlerle kemik ve kemik iliği hücrelerinin iskemisi sonucu nekroza gitmesi olayıdır. Avasküler nekroz, bünyesinde ölü hücre rezorpsiyonu ve yeni kemik oluşumunun bir arada görüldüğü bir süreci içerir. Patofizyolojide ana sebep ne olursa olsun ortak sonuç subkondral mikrosirkülasyonun etkilenmiş olmasıdır. İskemi sebebi olarak genellikle travma (kırık ya da çıkıklar sonucu) ile vasküler yapıların doğrudan hasarlanması, trombüs ya da yağ embolisi sonucu damar oklüzyonu ya da kemik içi liposit hipertrofisi sonucu ekstravasküler kompresyon suçlanmaktadır. Avasküler nekrozda patofizyoloji ve olası risk faktörlerinin bilinmesi erken tanı ve eklem koruyucu yaklaşımlar açısından önemli olacaktır.
\end{abstract}

Anahtar sözcükler: avasküler nekroz; osteonekroz; etiyoloji; patofizyoloji; kemik canlılı̆̆ı
Osteonecrosis (avascular necrosis, bone infarction, aseptic necrosis) is a phenomenon where bone and bone marrow cells go to necrosis as a result of ischemia. Osteonecrosis involves a process in which dead cell resorption and new bone formation are seen together. Whatever the main cause in pathophysiology, the common result is that subchondral microcirculation is affected. Trauma (as a result of fractures or dislocations) and direct damage to vascular structures, vascular occlusion due to thrombus or fat embolism, or extravascular compression as a result of intra-osseous lipocyte hypertrophy are usually blamed for ischemia. Knowing the pathophysiology and possible risk factors in osteonecrosis will be important for early diagnosis and joint sparing approaches.

Key words: avascular necrosis; osteonecrosis; etiology; pathophysiology; bone viability

\section{$\mathbf{A}$} vasküler nekroz literatürde osteonekroz, aseptik nekroz, kemik infarktüsü ve spontan osteonekroz şeklinde farklı isimlerle anılmaktadır. Farklı etiyolojik nedenlerle ortaya çıkan avasküler nekroz, etkilediği kemiğin epifiz, metafiz ya da diyafizini tutabilir. Klinik belirtilerin ortaya çıkmasında, kemiğin tutulduğu bölgesinden ziyade, tutulum alanının büyüklüğünün ve eklem yüzeyine yakınlığının ilişikili olduğu bilinmektedir. ${ }^{[1]}$ Etiyolojiden bağımsız olarak avasküler nekroz trabeküler kemik ve kemik iliğini tutar. Genellikle kortikal kemik, kollateral beslenme özelliğinden dolayı bu süreçten etkilenmez. ${ }^{[2]}$ Vücutta bulunan bazı kemikler ise (kalça, diz, talus, skafoid...) gerek anatomik yapıları, gerekse beslenme şekilleriyle avasküler nekroza daha duyarlıdır.

Bu yazıda kemik iskemisinin yapısal sonuçlarına odaklanılmakta olup, patofizyolojik açıdan avasküler nekroz için olası risk faktörleri ve etiyolojik nedenler anlatılmaktadır.

\section{TANIMLAMALAR, ETIYOLOJISI VE ETIYOPATOLOJISI}

Avasküler nekroz (osteonekroz, kemik infarktüsü, aseptik nekroz), çeşitli nedenlerle kemik ve kemik iliği hücrelerinin iskemisi sonucu nekroza gitmesi olayıdır. Kemikte meydana gelen ölüm işlemine vücudun verdiği reaktif yanıtlarla kemik yapımının uyarılması birlikte seyreder. Genel olarak avasküler nekroz etiyolojisi ne olursa olsun sonuçta kemik hücresinin ölümüne giden bir dizi ortak patolojik yolak meydana gelmektedir (Şekil 1). ${ }^{[3]}$

Avasküler nekroz sürecinden temel olarak 3 ana mekanizma suçlanmaktadır; vasküler hasar, mikrotrombüs ve ekstravasküler bası. Bu mekanizmaların tamamında kemik içi basınç artar, kan akımı yavaşlarve durur. Sonuç olarak iskemi ve nekroz görülmeye başlar. Şekil 1'de bu üç temel mekanizma toplu halde verilmiştir. Bu üç ana mekanizma daha ayrıntılı olarak aşağıda anlatılmıştır.

- İletişim adresi: Dr. Oğuzhan Korkmaz, Göztepe Mah. Metin Sokak No: 3 Medipol Mega Hastaneler Kompleksi, Bağcılar, İstanbul Tel: 0507 - 6638007 e-posta: droguzhankorkmaz@gmail.com

- Geliş tarihi: 9 Eylül $2020 \quad$ Kabul tarihi: 22 Eylül 2020 


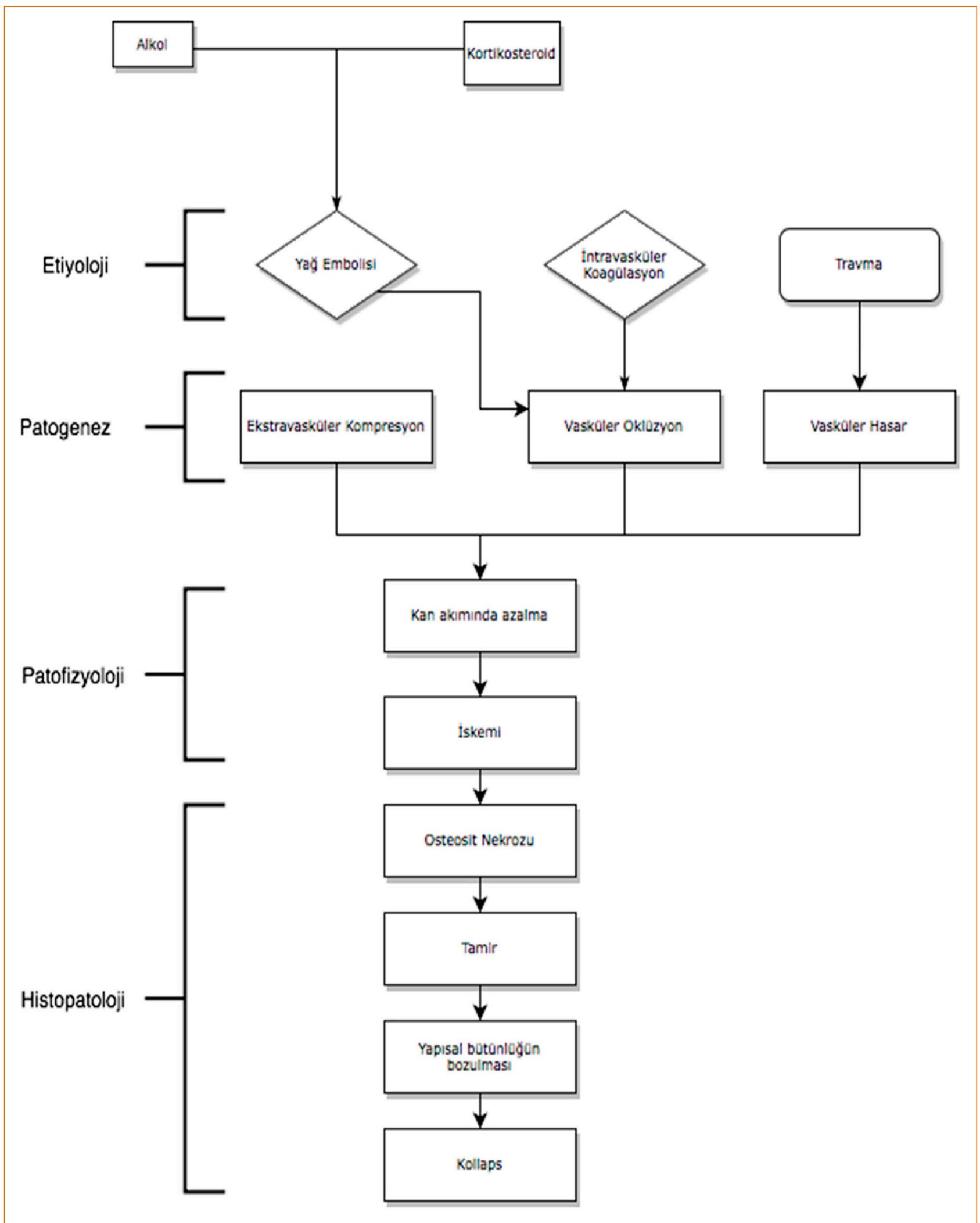

Şekil 1. Avasküler nekrozda suçlanan vasküler hasarlanma, mikrotrombüs ve esktravasküler bası nedeniyle kemik içi basınç artışına bağlı olarak kemik kan akımı yavaşlayarak durur. Sonuç olarak iskemi ve nekroz görülür. Nekrotik kemiğin tamir olayları başlar, ancak nekrotik dokunun rezorpsiyonu ve yeni kemik oluşumu yavaş ilerleyen olaylardır. Bu süre içerisinden yapısal zayıflığından dolayı subkondral kemikte çökme, ayrışma ve kırıklar görülebilir. 


\section{Vasküler Hasar}

Travma sonrası kırık ya da çıkık gelişen kemiklerde vasküler yapıların zarar görmesine bağlı olarak iskemi gelişmesi olası bir durumdur. Özellikle kalça, diz, omuz, skafoid, talus ve lunatum gibi bölgelerin anatomisi ve hemodinamisi gereği, travmatik olaylar sonrasında avasküler nekroza gidebileceği bilinmektedir. ${ }^{[4]}$ Genellikle travma olayını takiben avasküler nekroz gerçekleşmesi benzer patolojik yolakla gerçekleştiğinden, en sık avasküler nekroz görülen kalça bölgesi detaylandırılacaktır.

Femur başı medial sirkumfleks ve lateral sirkumfleks arterlerin dallarından beslenir. Bu dallar femur başını metafizinden ve epifizin eklem yüzü oluşturmayan bölgelerinden girerek besler. ${ }^{[5]}$ Medial sirkumfleks arterin derin dalı femur başı beslenmesinde en önemli damardır. ${ }^{[6,7]} \mathrm{Bu}$ damarların yerleri onları travmalara duyarlı hale getirir. ${ }^{[8]}$ Femur boynunun intrakapsüler kırıkları bu damarların doğrudan zarar görmesine neden olabilir. Bu tarz kırıklar sonrasında avasküler nekroz görülme insidansının topluma oranla nispeten daha fazla olduğu bildirilmiştir. ${ }^{[9]}$ Ayrıca kırık tipinin, redüksiyonun yeterliliği ile ilişkisini ve avasküler nekroz gelişim sürecini araştıran çalışmalar mevcuttur. Garden yaptığı çalışma$\mathrm{da}$, radyografik olarak ameliyat sonrası malredüksiyonu mevcut hastaların \%65,4'ünde avasküler nekroz ve kollaps, açık redüksiyon ve internal tespitle doğru pozisyonda tespit edilen boyun kırıklarında ise \%6,6'sında avasküler nekroz geliştiğini bildirmiştir. ${ }^{[10]}$ Aynı çalışmada kabul edilebilir redüksiyonun AP grafide femur şaftının medial korteksi ile femur boynunun ortası arasındaki açının $155^{\circ}-180^{\circ}$ arasında olması gerektiği bildirilmiştir. Bununla birlikte valgusta tespit edilen femur boyun kırıklarının da avasküler nekroz gelişimi açısından büyük risk altında olduğu bildirilmiştir. ${ }^{[11]}$ Bir başka çalışmada ise Garden tip I ve II femur boyun kırıklarının tip III ve IV kırıklara göre avasküler nekroz açısından düşük riskli olduğu bildirilmiştir. ${ }^{[12]}$

Femur başının beslenmesini sağlayan damarsal yapıların uzaklığından dolayı intertrokanterik bölgenin ekstrakapsüler kırıkları avasküler nekroz açısından düşük insidansa sahiptir. ${ }^{[13]}$

Kalça çıkıkları da femur başının damarsal bütünlüğü bozacak yaralanmalara sebep olabilir.[7,14-16] Medial sirkumfleks arterin derin dalı, posterior kalça çıkığında $\mathrm{m}$. obutaratorus eksternusun önüne ve m. kuadratus femorisin arkasına doğru yer değiştirdiğinden yaralanabilir. ${ }^{[7,17]}$ Posterior kalça çıkığı sonrasında gelişen femur başı avasküler nekroz oranları \%5-60 arasında bildirilmiştir. ${ }^{[14-16]}$

\section{İntravasküler Oklüzyon}

Damar içi tıkanıklıklara sebep olan durumlarda da kemik beslenmesi bozulacağından avasküler nekroz görülebilir. Bu tıkanıklıklar direkt olarak pıhtı veya yağ embolisi sebepli olabileceği gibi, orak hücreli anemi, polistemi, hemoglobulinopatiler ile lenfoproliferatif hastalıklar zemininde de gelişebilir.

Orak hücreli anemisi olan hastalarda avasküler nekroz gelişme riski farklı çalışmalarda \%11-37 arasında bildirilmiştir. ${ }^{[18-20]} \mathrm{Bu}$ hastalarda düşük oksijen basıncında eritrositlerin oraklaştığı kabul edilir. Oraklaşan eritrositlerin de birbirlerine yapışarak özellikle kan akımının düşük olduğu osseöz vasküler yapılarda tıkanıklığa neden olarak avasküler nekroz yol açtığı kabul edilmektedir. ${ }^{[21]}$

Koagülasyon faktörlerinin anormallikleri de yine damar içinde tıkanıklara neden olmaktadır. Hipofibrinoliz ya da trombofili ile giden genetik hastalıklar trombüs oluşumuna zemin oluşturarak vasküler tıkanıklık sonucu kemik beslenmesini bozar. ${ }^{[8,22-25]}$ Glueck CJ ve ark. plazminojen aktivatör inhibitörü seviyesinin yükselmesine sekonder görülen hipofibrinolizisin, avasküler nekrozu olan hastalarda \%31 oranında görüldüğünü bildirmiştir. ${ }^{[23]}$ Trombofili için ise geriye dönük bir çaIışmada, avasküler nekroz görülen hastaların kontrol grubuna göre Faktör $V$ Leiden mutasyonun anlamlı derecede yüksek olarak görüldüğgü bildirilmiştir. ${ }^{[25]}$

Genetik hastalıkların yanı sıra avasküler nekroz gelişmiş hastalarda artmış koagülasyon faktör seviyeleri belirtilmiştir. Jones ve ark. avasküler nekroz gelişen hastaların \%82'sinde en az bir adet, \%50'sinde de iki ya da daha fazla koagülasyon faktör anormalliği olduğunu bildirmişlerdir. ${ }^{[26]}$ Benzer olarak idiyopatik veya sekonder olarak avasküler nekroz gelişen hastalarda kontrol grubu ile kıyaslandığında lipoprotein A ve Von Willebrand faktörün yüksek olduğu, protein $C$ ve $S$ seviyelerinin ise düşük olduğu bildirilmiştir. ${ }^{[27]}$

\section{İntraosseöz Ekstravasküler Kompresyon}

Bu etiyolojik neden için, rijit (sert) duvarlı bir odanın içerisinde seyreden sıkıştırılabilen bir boru sistemi üzerinden akış miktarının bu sıkışabilen borular üzerindeki basınca bağlı olduğunu açıklayan Starling kuramıyla açıklanabilir (Şekil 2). İntraosseöz ekstravasküler boşluk içindeki basınç yükselmeleri, içinden geçen küçük damarlardaki kan akışını azaltabilir.

Kemik iliği alanındaki lipit birikimi ve adiposit hipertrofisi, intraosseöz ekstravasküler basıncın dolaşımı azaltabildiği iki baskın klinik durumdur. ${ }^{[22]}$ Genellikle kortikosteroid veya alkol alımı ile ilişkili olarak, ekstravasküler basınçtaki artışın arteriyel giriş veya venöz 


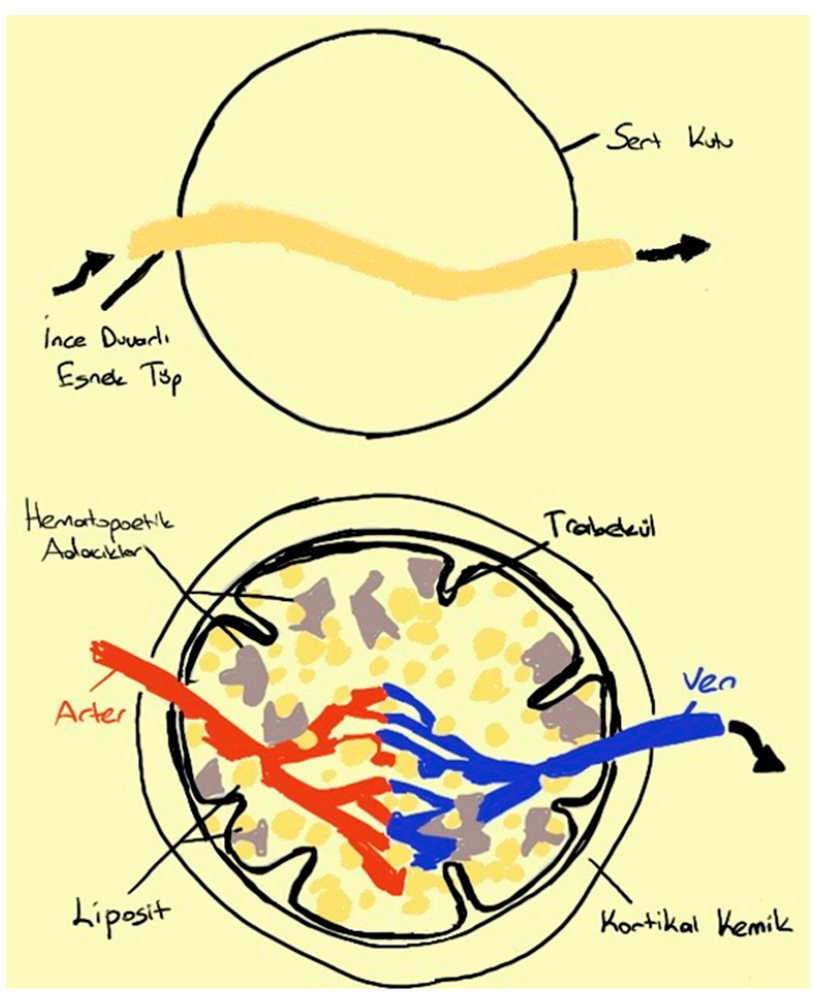

Şekil 2. Starling direnç kavramına göre sert bir oda içerisindeki basınç artışı, odanın içerisinden geçen esneyebilen bir tübün içerisindeki sıvı akışını azaltır. Buna bağlı olarak kemik dokuda, intraosseöz ekstravasküler bölümde basınç artışına neden olan durumlarda mikrosirkülasyon yavaşlayarak iskemi ve nekroza neden olabilecek kadar azalabilir.

çıkış için bir obstrüksiyon yarattığı ve femur başındaki kemik iliği elemanlarının ve osteositlerin iskemisine yol açtığı varsayılmaktadır.

Geriye dönük çalışmalarda kortikosteroid kullanımı ile ilişkili avasküler nekroz olguların \%10-30'unda gösterilmiştir. ${ }^{[22]}$ Kortikosteroid kullanımının avasküler nekroz gelişimine katkısını, altta yatan durumdan ayırmak zor olsa da, 22 çalışmadan oluşan kapsamIı bir metaanaliz çalışmasında altta yatan hastalık ile avasküler nekroz arasında bir ilişki bulanamadığı bildirilmiştir. ${ }^{[28]}$ Kortikosteroid dozunun, kullanım süresini inceleyen birçok çalışma yapılmıştır. İleriye dönük kohort çalışmaları günlük ortalama $>20 \mathrm{mg}$ /gün dozun avasküler nekroz için anlamlı bir risk ile ilişkili olduğunu göstermiştir. ${ }^{[29]}$ Felson ve Anderson, oral kortikosteroid alımındaki her $10 \mathrm{mg} /$ gün artış için avasküler nekroz gelişim riskinde 4,6 kat artış saptamıştır. ${ }^{[28]}$

Aşırı alkol tüketimi de avasküler nekroz gelişimi açısından riskli durumlardandır. Matsuo ve ark., haftada $400 \mathrm{~mL}$ 'den fazla alkol tüketen bireylerin, hiç alkol tüketmeyenlere göre avasküler nekroz gelişim riskinde 9,8 kat artış olduğunu bildirdi. Ayrıca haftada 1000 mL'den fazla alkol tüketen kişilerde bu riskin 17,9 katına yükseldiği bildirilmiştir. ${ }^{[30]}$

Gaucher hastalığı, avasküler nekroz gelişimine intraosseöz ekstravasküler basıncı artırarak sebep olur. ${ }^{[31]}$ Beta-glukoserebrosidaz eksikliğinden ötürü, Gaucher hastalığı olan hastalar, histiyositlerin lizozomlarında, glukoserebrosid biriktirirler ve zamanla önemli bir ekstravasküler basınç artışına neden olur. $\mathrm{Bu}$ artan basınç, sırayla, iskemiye yol açan vasküler elemanları sıkıştırabilir. ${ }^{[22]}$

Avasküler nekroz ile ilgili birçok diğer etiyolojik nedenler retrospekif olgu-kontrol çalışalarıyla bildirilmiştir. Hiperlipidemi, hiperürisemi, pankreatit, lösemi, lenfoma, hipertrigliseridemi potensiyel olarak osteonekroz etiyolojisinde suçlanmaktadır. Ayrıca gebelik, radyasyon maruziyeti, kemik iliği transplantasyonu ve malignitelerde de avasküler nekroz gelişim riskini artırmaktadır.

\section{PATOFiZYOLOjisi}

\section{Hücre ve Doku Nekrozu}

Avasküler nekroz, tipik bir hücre ölümü paterni ve karmaşık bir kemik rezorpsiyonu ve oluşumu süreci ile karakterizedir. Avasküler nekrozun en erken belirtisi, kemik iliği ödemi ve takiben gelişen hematopoetik hücre ile adiposit nekrozudur. Osteosit ölümü anoksiyi takiben 2-3 saat içerisinde gerçekleşirken, histolojik belirtiler 24-72 saat içerisinde ortaya çıkar. Osteosit nekrozu, başlangıçta çekirdek piknozisi ve boş osteosit lakünü olarak yansır. Takiben reaktif hiperemi ve kılcal damar revaskülarizasyonu, nekrotik bölgenin çevresinde bir dereceye kadar gerçekleşir ve kan damarlarının girişi ile, ölü kemiklerin tamamen yerine geçerek kemik rezorpsiyonu ve üretimden oluşan bir onarım işlemi başlar. Yeni canlı kemik ölü trabeküllerin üzerine ölü kemik kısmi rezorpsiyonu ile lamine edilir. Subkondral trabeküllerde, kemik rezorpsiyonu trabeküllerin yapısal bütünlüğünün kaybına, subkondral kırığa ve eklem uyuşmazlığına yol açar. Yapısal bütünlük ve subkondral kırık kaybına sebep olan nekrozun kendisi değil, daha ziyade onarım süreci ve bu sürecin de özellikle rezorptif komponentidir. ${ }^{[32]}$ Bütün bu yapım-yıkım işlemi "cutting cone" adı verilen kompleks bir yapı ile tamamlanır (Şekil 3). Bu histopatolojik değişiklikler skleroz ve berraklık görünümü oluşturan radyografik bulguların sebebidir. Berraklık alanları kemik rezorpsiyonunu yansıtırken, skleroz alanları hem yaşayan onarıcı kemik hem de ölü trabeküllerden oluşur. 


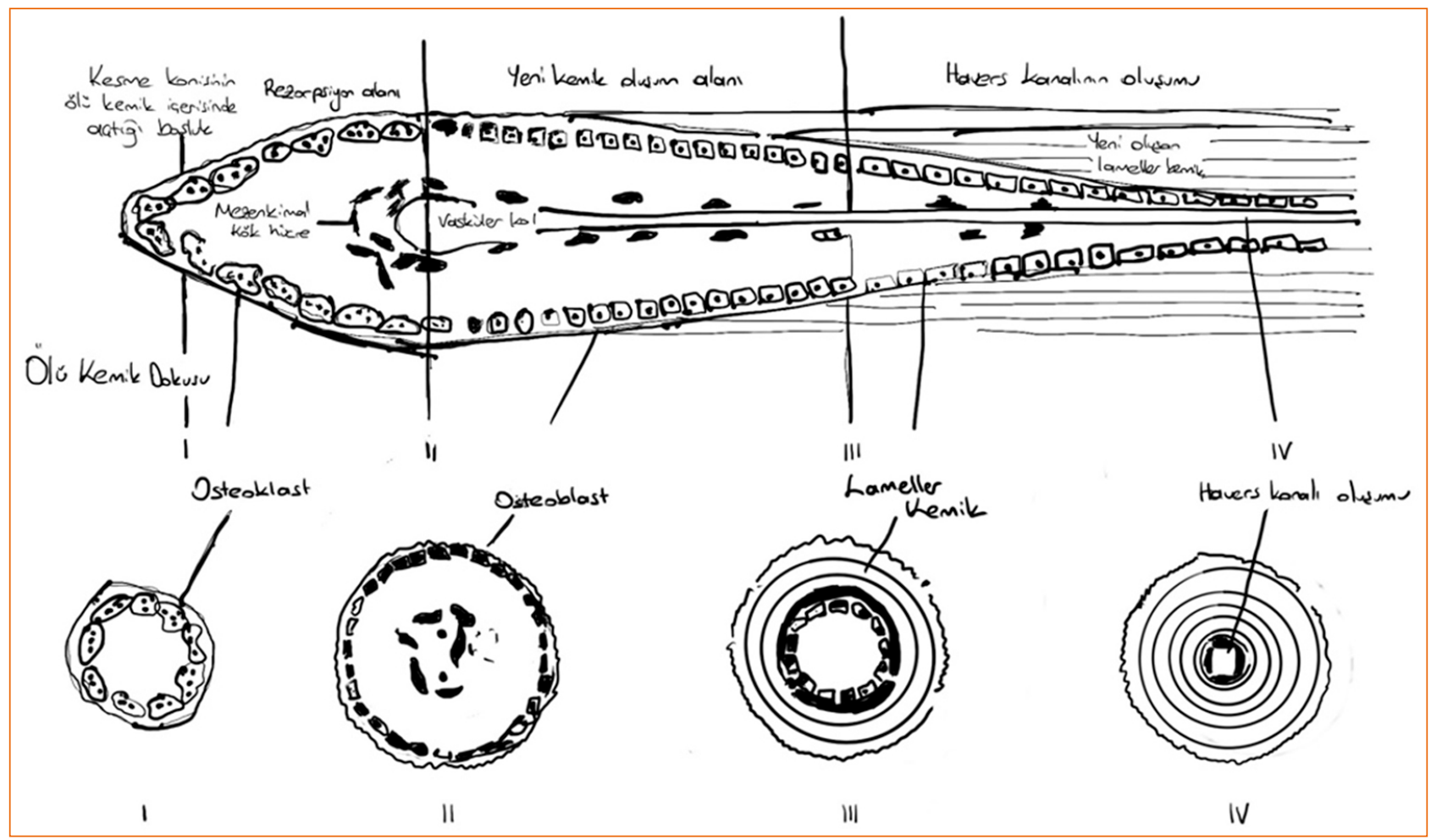

Şekil 3. Kesme konisi (cutting cone). I: Osteoklastları nekrotik kemik doku içerisinde rezorpsiyonu. Bu bölgede boşlukları osteoklastlar doldur ve vasküler kol ile mezenkimal hücreler nekrotik doku içerisine migre olur. II: Yeni kemik dokusunun oluşmaya başladığı ve osteoblastların görüldüğü alan. III-IV: Yeni kemik dokusunda lameller dizilim ve Haversian kanal sisteminin oluşması.

\section{Mikrosirkülasyonun Bozulması}

Avasküler nekrozun, patofizyolojisinde temel nokta osteositlerin anoksisidir. Doğal olarak kemik beslenmesini bozan her türlü vasküler neden avasküler nekroz ile sonuçlanabilir. Bazı kemikler ise kanlanma özelliği, geometrisi ya da anatomisi gereği beslenme açısından fakir olup, herhangi bir etiyolojik neden sonrasında avasküler nekroza girme eğiliminde olur. Daha önce belirtildiği gibi, üç patojenik mekanizma ile kemik kan akışında azalma olabilir: kırık veya çıkık ile vasküler kesinti, trombüs veya embolik yağdan intravasküler oklüzyon ve intraosseöz ekstravasüler kompresyon. (Şekil 1)

Yapılan bir çalışmada intraosseöz kan akımının 1,6 kat azalması sonrasında ölçülen intraosseöz pO2 oranının 75 mmHg'den, 50 mmHg'ye kadar düştüğü gösterilmiştir ki bu da avasküler nekroz gelişimi için yeterli anoksik miktar olarak belirtilmiştir. ${ }^{[33]}$

\section{İntraosseöz Hipertansiyon}

Venöz çıkış obstrüksiyonu ve venöz staza sekonder gelişen avasküler nekrozlarda, yapılan ölçümlerde kemik içi basıncın artmış olduğu bildirilmiştir. ${ }^{[34]}$ Normal kemik iliği basınçlarının yaklaşık 15 mmHg olduğu ve 30 mmHg'nin üzerindeki değerlerin anormal olduğu bildirilmiştir. Ancak intraosseöz hipertansiyonun, liposit artışı ya da Gaucher hücrelerinin varlığı gibi ekstravasküler boşlukta yer kaplayan hücreler olması nedeniyle tam olarak ölçülemeyeceği de savunulmaktadır. Bu yüzden intraosseöz hipertansiyonun avasküler nekroza özgü olmayan ve sekonder gelişen bir bulgu olduğunu savunan görüşler de vardır. ${ }^{[22,35]}$

Sonuç olarak, bütün bu patofizyolojik ve etiyolojik faktörler göz önünde bulundurulduğunda, subkondral kemikte çökme olması eklem kaybına kadar gidebilecek patolojik bir yolağa neden olur. Bu yüzden erken tanı avasküler nekroz tedavisinde önem taşımaktadır.

\section{KAYNAKLAR}

1. Lamb JN, Holton C, O'Connor P, Giannoudis PV. Avascular necrosis of the hip. BMJ Clin Res 2019;365:2178. https://doi. org/10.1136/bmj. 12178

2. Kumar V, Abbas A, Aster J. Robbins Basic Pathology, 10th ed. Elsevier Health Sciences, 2017. 
3. Shah KN, Racine J, Jones LC, Aaron RK. Pathophysiology and risk factors for osteonecrosis. Curr Rev Musculoskelet Med 2015;8(3):201-209. Crossref

4. Schmitz MR, De Hart MM, Qazi Z, Shuler FD. Basic Sciences, Section 1: Bone. In: Miller MD, Thompson SR, editors. Review of Orthopaedics, 7th ed. Philadelphia: W.B. Saunders; 2016. p.1-147

5. Johnson EO, Soultanis K, Soucacos PN. Vascular anatomy and microcirculation of skeletal zones vulnerable to osteonecrosis: vascularization of the femoral head. Orthop Clin N Am 2004;35(3):285-91. Crossref

6. Zlotorowicz M, Czubak J, Caban A, Kozinski P, BoguslawskaWalecka R. The blood supply to the femoral head after posterior fracture/dislocation of the hip, assessed by CT angiography. Bone Joint J 2013;95-B(11):1453-7. Crossref

7. Zlotorowicz M, Szczodry M, Czubak J, Ciszek B. Anatomy of the medial femoral circumflex artery with respect to the vascularity of the femoral head. J Bone Joint Surg Br 2011;93$B(11): 1471-4$. Crossref

8. Assouline-Dayan Y, Chang C, Greenspan A, Shoenfeld $\mathrm{Y}$, Gershwin ME. Pathogenesis and natural history of osteonecrosis. Semin Arthritis Rheum 2002;32(2):94-124. Crossref

9. Slobogean GP, Sprague SA, Scott T, Bhandari M. Complications following young femoral neck fractures. Injury 2015;46(3):484-91. Crossref

10. Garden RS. Malreduction and avascular necrosis in subcapital fractures of the femur. J Bone Joint Surg 1971;53-B(2):18397. Crossref

11. Barnes R, Brown JT, Garden RS, Nicoll EA. Subcapital fractures of the femur. A prospective review. J Bone Joint Surg $\mathrm{Br}$ 1976;58-B(1):2-24. Crossref

12. Nikolopoulos KE, Papadakis SA, Kateros KT, Themistocleous GS, Vlamis JA, Papagelopoulos PJ, Nikiforidis PA. Long-term outcome of patients with avascular necrosis, after internal fixation of femoral neck fractures. Injury 2003;34(7):525-8. Crossref

13. Barquet A, Mayora G, Guimaraes JM, Suárez R, Giannoudis PV. Avascular necrosis of the femoral head following trochanteric fractures in adults: a systematic review. Injury 2014;45(12):1848-58. Crossref

14. Dwyer AJ, John B, Singh SA, Mam MK. Complications after posterior dislocation of the hip. Int Orthop 2006;30(4):2247. Crossref

15. McKee MD, Garay ME, Schemitsch EH, Kreder HJ, Stephen DJ. Irreducible fracture-dislocation of the hip: a severe injury with a poor prognosis. J Orthop Trauma 1998;12(4):223-9. Crossref

16. Hougaard K, Thomsen PB. Traumatic posterior dislocation of the hip -prognostic factors influencing the incidence of avascular necrosis of the femoral head. Arch Orthop Trauma Surg 1986;106(1):32-5. Crossref

17. Gautier E, Ganz K, Krügel N, Thomas Gill, Ganz R. Anatomy of the medial femoral circumflex artery and its surgical implications. J Bone Joint Surg Br 2000;82(5):679-83. Crossref

18. Mukisi-Mukaza M, Elbaz A, Samuel-Leborgne Y, Kéclard L, Le Turdu-Chicot C, Christophe-Duchange E, Mérault G. Prevalence, clinical features, and risk factors of osteonecrosis of the femoral head among adults with sickle cell disease. Orthopedics 2000;23(4):357-63. https://pubmed.ncbi.nlm. nih.gov/10791585/

19. Matos MA, dos Santos Silva LL, Brito Fernandes R, Malheiros CD, Pinto da Silva BV. Avascular necrosis of the femoral head in sickle cell disease patients. Ortop Traumatol Rehabil 2012;14(2):155-60. Crossref
20. Tanaka KR, Clifford GO, Axelrod AR. Sickle cell anemia (homozygous S) with aseptic necrosis of femoral head. Blood 1956;11(11):998-1008. Crossref

21. Colin Y, Le Van Kim C, El Nemer W. Red cell adhesion in human diseases. Curr Opin Hematol 2014;21(3):186-92. Crossref

22. Aaron RK, Gray R. Osteonecrosis: etiology, natural history, pathophysiology, and diagnosis. In: Callaghan JJ, Rosenberg AG, Rubash HE, editors. The Adult Hip. Philadelphia: Lippincott Williams \& Wilkins; 2007. p.465-76.

23. Glueck CJ, Freiberg RA, Boppana S, Wang P. Thrombophilia, hypofibrinolysis, the eNOS T-786C polymorphism, and multifocal osteonecrosis. J Bone Joint Surg Am 2008;90(10):2220-9. Crossref

24. Zalavras CG, Vartholomatos G, Dokou E, Malizos KN. Genetic background of osteonecrosis: associated with thrombophilic mutations? Clin Orthop Relat Res 2004;422:251-5. Crossref

25. Hadjigeorgiou G, Dardiotis E, Dardioti M, Karantanas A, Dimitroulias A, Malizos K. Genetic association studies in osteonecrosis of the femoral head: mini review of the literature. Skeletal Radiol 2008;37(1):1-7. Crossref

26. Jones LC, Mont MA, Le TB, Petri M, Hungerford DS, Wang P, Glueck CJ. Procoagulants and osteonecrosis. J Rheumatol 2003;30(4):783-91. https://www.jrheum.org/ content/30/4/783.long

27. Zalavras C, Dailiana Z, Elisaf M, Bairaktari E, Vlachogiannopoulos P, Katsaraki A, Malizos KN. Potential aetiological factors concerning the development of osteonecrosis of the femoral head. Eur J Clin Invest 2000;30(3):215-21. Crossref

28. Felson DT, Anderson JJ. Across-study evaluation of association between steroid dose and bolus steroids and avascular necrosis of bone. Lancet 1987;1(8538):902-6. Crossref

29. Aaron RK, Voisinet A, Racine J, Ali Y, Feller ER. Corticosteroidassociated avascular necrosis: dose relationships and early diagnosis. Ann N Y Acad Sci 2011;1240:38-46. Crossref

30. Matsuo K, Hirohata T, Sugioka Y, Ikeda M, Fukuda A. Influence of alcohol intake, cigarette smoking, and occupational status on idiopathic osteonecrosis of the femoral head. Clin Orthop Relat Res 1988;(234):115-23. Crossref

31. Deegan PB, Pavlova E, Tindall J, Stein PE, Bearcroft P, Mehta A, Hughes D, Wraith JE, Cox TM. Osseous manifestations of adult Gaucher disease in the era of enzyme replacement therapy. Medicine (Baltimore) 2011;90(1):52-60. Crossref

32. Glimcher MJ, Kenzora JE. Nicolas Andry award. The biology of osteonecrosis of the human femoral head and its clinical implications: I. Tissue biology. Clin Orthop Relat Res 1979;(138):284-309. https://pubmed.ncbi.nlm.nih. gov/445912/

33. Kiaer $T$, Pedersen NW, Kristensen KD, Starklint $H$. Intraosseous pressure and oxygen tension in avascular necrosis and osteoarthritis of the hip. J Bone Joint Surg Br 1990;72$B(6): 1023-30$. Crossref

34. Hungerford DS, Lennox DW. The importance of increased intraosseous pressure in the development of osteonecrosis of the femoral head: implications for treatment. Orthop Clin North Am 1985;16(4):635-54. https://pubmed.ncbi.nlm. nih.gov/3903603/

35. Jones JP Jr. Etiology and pathogenesis of osteonecrosis. Semin Arthroplasty 1991;2:160-8. 